\title{
Mortality of workers exposed to toluene diisocyanate in the polyurethane foam industry
}

\author{
Teresa M Schnorr, Kyle Steenland, Grace M Egeland, Mark Boeniger, David Egilman
}

\begin{abstract}
Objective-To evaluate cancer mortality among United States workers exposed to toluene diisocyanate (TDI) in the manufacture of polyurethane foam.

Methods-This cohort mortalilty study included 4611 men and women employed in four polyurethane foam plants for at least three months between the late 1950s and 1987. The mortality experience of the cohort was then compared with that of the general United States population.

Results-Current and past industrial hygiene data indicated that air concentrations in 1984-5 were below the current United States standard of $0.04 \mathrm{mg} / \mathrm{m}^{3}$ but exceeded the standard before 1980 . Mortality from rectal cancer (standardised mortality ratio (SMR) $2 \cdot 78,95 \%$ confidence interval (95\% CI) $0.57-8 \cdot 13)$ and non-Hodgkin's lymphoma (SMR 1.54, 95\% CI 0.42-3.95) were increased, but not significantly. There was one male breast cancer. However, breast cancer was not increased in women (SMR 0.74). No other cancer category had an increased number of deaths compared with the general population. Only non-Hodgkin's lymphoma and Hodgkin's disease showed a possible relation with time since first employment and no cancer death category showed a strong relation with duration of employment. Mortality from non-malignant respiratory disease was not increased (SMR 0.86).
\end{abstract}

Conclusions-This young cohort has few deaths and short follow up. The findings are therefore not conclusive. Further years of follow up will enable better evaluation of mortality.

\section{(Occup Environ Med 1996;53:703-707)}

Keywords: isocyanates; cancer; mortality

Toluene diisocyanate (TDI) is a colourless to pale yellow liquid with a sharp pungent odour. It is used primarily in the synthesis of polyurethane foams. Flexible polyurethane foam is used mainly in car seats, furniture, and bedding and rigid foams are used in insulation. The foam is produced by an exothermic reaction which evolves carbon dioxide. Thus TDI can be carried into the air above the foam. Air concentrations immediately above the foam during the rise may be as high as $72 \cdot 4 \mathrm{mg} / \mathrm{m}^{3}$ (10 ppm). ${ }^{.}$An estimated 34000 workers were exposed to TDI in the United States during the period 1981-3 (unpublished data from the National Institute for Occupational Safety and Health (NIOSH) National occupational exposure survey (NOES), Cincinnati, Ohio: NIOSH, 1983).

The isocyanates have been of concern to industrial toxicologists since the 1940s with the first clinical report of the health consequences of exposure to them reported in $1951 .^{2}$ Since that time, TDI toxicity has been widely studied, primarily for asthma, sensitisation, and chronic decrements in lung function. ${ }^{3}$

Methylene diphenylisocyanate (MDI) and TDI were mutagenic in an Ames test. ${ }^{4}$ This effect was ascribed to the amine analogues formed during the hydrolysis of isocyanates, a reaction that may occur when isocyanate vapours are caught on moist surfaces. Aromatic amines (2,4-toluene diamine and 2,6-toluene diamine) have been detected in the chemically hydrolysed urine of polyurethane foam workers ${ }^{5}$ and 2,4-toluene diamine has been shown to produce cancer in rats dosed orally. ${ }^{6}$

Two animal carcinogenicity studies of TDI have been conducted. An animal gavage study $^{7}$ found an increased incidence of tumours in male rats (fibromas or fibrosarcomas and pancreatic acinar cell adenomas), female rats (fibromas or fibrosarcoma, pancreatic islet cell adenomas, neoplastic nodules of the liver, and mammary gland fibroadenomas), and female mice (haemangiomas or haemangiosarcomas and hepatocellular adenomas). The tumours followed a significant dose-response trend. An inhalation study of male and female mice exposed to 0.36 and $1.1 \mathrm{mg} / \mathrm{m}^{3}$ found no significant increase in tumour incidence. ${ }^{8}$ The International Agency for Research on Cancer (IARC) evaluated these two studies and classified TDI as having sufficient evidence for carcinogenicity in animals. ${ }^{9}$ Evidence for human carcinogenicity was considered inadequate for evaluation.

More recently, two cohort studies of populations exposed to TDI have been published. One study indicated a non-significant increased incidence of rectal cancer (standardised incidence ratio (SIR) $1.66,95 \%$ confidence interval $(95 \% \mathrm{CI}) \quad 0.61-3.61)$ and non-Hodgkin's lymphoma (SIR $1.53,95 \%$ CI $0 \cdot 42-3.91) .{ }^{10}$ Another study found excess pancreatic (standardised mortality ratio (SMR) $2 \cdot 71,95 \%$ CI $1 \cdot 00-5 \cdot 95)$ and lung (SMR $1 \cdot 76,95 \%$ CI $1 \cdot 00-2 \cdot 85)$ cancer mortality among women only. ${ }^{11}$ However, the 
polyurethane industry, and the study cohorts, were young limiting the time since first exposure and number of deaths observed in the studies.

The current Occupational Safety and Health Administration (OSHA) standard for exposure to TDI is $0.15 \mathrm{mg} / \mathrm{m}^{3}$ short term exposure limit (STEL) and $0.04 \mathrm{mg} / \mathrm{m}^{3}$ time weighted average (TWA). The standard was set to protect against respiratory irritation and asthma like symptoms.

\section{Methods}

A preliminary file of about 14500 people who worked for at least one day at four polyurethane manufacturing plants was created from work history records. From this file, about 6300 men and women were identified who worked for a minimum of three months at the plants. The final study population was limited to the 4611 workers employed for at least three months in an exposed department or job between the date polyurethane production began (between 1958 and 1965) and the date the plant closed (1982 for plant D) or the date of data collection (1984). Three of the plants (A, B, and D) were manufacturing sites of moulded polyurethane foam car cushions. Plant C, which comprised $64 \%$ of the cohort, produced slab foam for use in the furniture and carpet industries. Detailed work histories, including job titles, departments, and transfer dates were obtained for plants $\mathrm{B}, \mathrm{C}$, and $\mathrm{D}$ ( $95 \%$ of the population). For plant A, department and job titles were not available. However, detailed dates of employment were obtained.

Past data on TDI air concentrations were obtained, when available, from company or state records. Data suspected of being an inaccurate representation of past exposures (such as use of insensitive or inaccurate analytical procedures or samples taken during accidents or spills), were rejected. Also, exposure surveys were conducted during 1984-5 at each of the three operating facilities included in this study (plant D stopped operating in 1982). The methods and results are described else- where. ${ }^{12}$ Personal breathing zone air samples for both isomers of TDI were collected over four-hour periods ${ }^{13}$ and stationary sampling was conducted for possible air contaminants: aliphatic amines, $\mathrm{N}$-nitrosamine compounds, toluenediamine, flame retardant compounds, acrylonitrile, methylene chloride, pyridine, acrolein, vinyl chloride, nitrogen dioxide, and respirable dust. ${ }^{13}$ Finally, mutagenic activity of both aerosol and vapour fractions of the air was assessed using TA98 and TA100 bacterial strains in the Ames Assay.

A person was considered to be exposed if company records indicated that he or she had worked for at least three months in a department or job known to have potential for TDI exposure. Although some exposed workers may also have held some unexposed jobs during employment at the plant, calculation of duration of exposure was based only on time spent in exposed jobs. In plant $A$, everyone was considered to be exposed because all worked in the same area and past exposure data indicated that exposure levels were similar throughout the plant.

The vital status of all people in the cohort was obtained to 31 December 1993. Follow up included inquiry through the Social Security Administration, Internal Revenue Service, National Death Index, and state bureaux of motor vehicles. Death certificates were obtained from state vital records offices for all dead members of the cohort and coded by a trained nosologist according to the revision of the international classification of disease (ICD) in effect at the time of death.

The mortality experience of the cohort was analysed with the use of the National Institute for Occupational Safety and Health (NIOSH) modified lifetable analysis system. ${ }^{14} \mathrm{~A}$ worker accumulated person-years at risk for every year of life after completion of the three month eligibility period. Person-years at risk continued to accumulate until either death, date last known (for people lost to follow up), or the study end date (for people alive on 31 December 1993). These person-years at risk were stratified by five-year age, calendar periods, and three strata of duration of exposure
Mean TDI air concentrations by plant and time period. Exposure data were not available in 1965-9 for plants $B, C$, and $D$, in 1970-4 for plant $C$, and in 1975-9 for plant $A$. The value for plant $C$ in 1975-9 was 0.001 , and in 1980-6 was 0.001 . The value for Plant $B$ in 1980-6 was 0.002 .

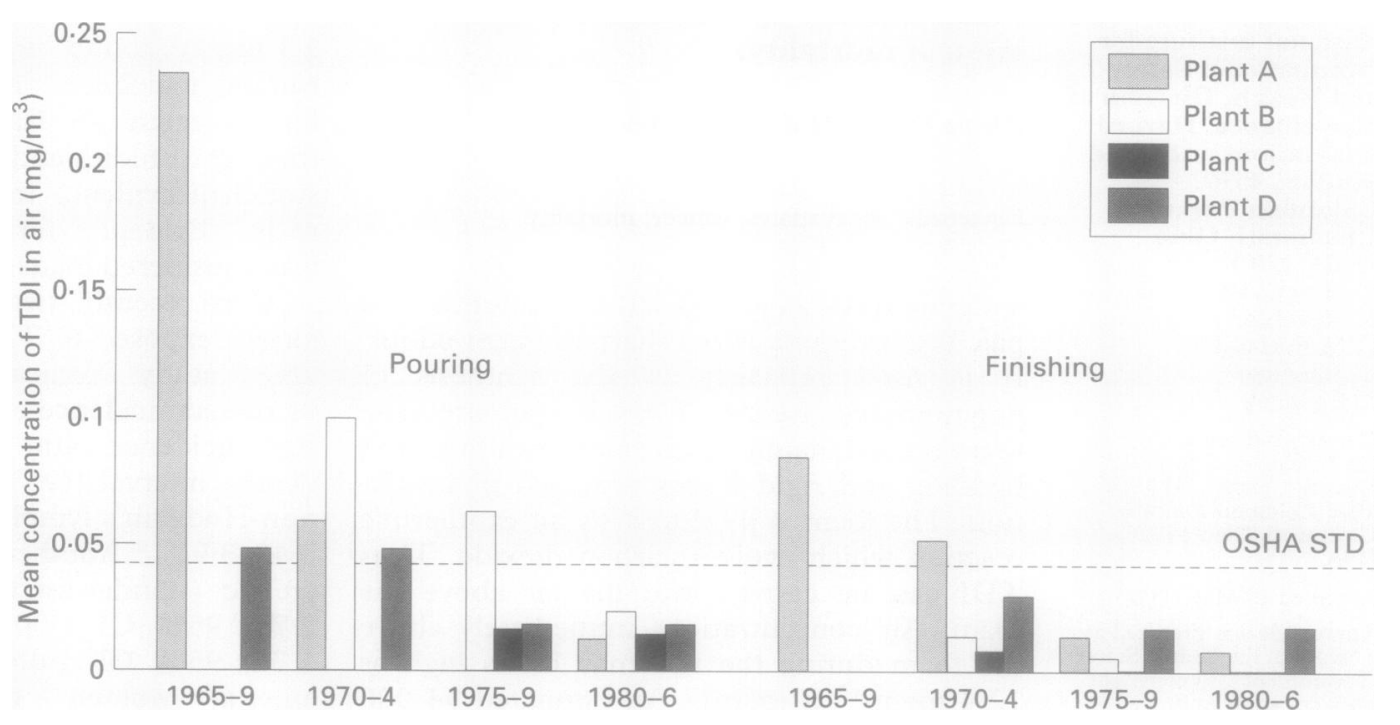


Table 1 Characteristics of the study population

\begin{tabular}{lc}
\hline Workers (n) & 4611 \\
Person-years at risk: & 90393 \\
Total & \\
Time since first exposure (y): & 47793 \\
$>10$ & 27754 \\
$>15$ & $2717(58 \cdot 9)$ \\
Sex (n (\%)): & $1893(41 \cdot 1)$ \\
Male & $3017(65 \cdot 5)$ \\
Female & $1385(30 \cdot 0)$ \\
Race (n (\%)): & $209(4 \cdot 5)$ \\
White & \\
Black & $4150(90 \cdot 0)$ \\
Other & $316(6 \cdot 9)$ \\
Vital status on 31 December 1993 (n (\%)): & $145(3 \cdot 1)$ \\
Alive & \\
Dead & 1948 \\
Unknown & $1894-1965$ \\
Year of birth: & 1972 \\
Median & \\
Range & $2 \cdot 4$ \\
Year of first employment (median) & $0 \cdot 25-26 \cdot 3$ \\
Duration of employment (y): & $19 \cdot 6$ \\
Mean & \\
Range & \\
Follow up (mean (y)) & \\
\hline
\end{tabular}

Table 2 Study population by plant

\begin{tabular}{lccll}
\hline Plant & Workers $(n)$ & $\begin{array}{l}\text { Person-years } \\
\text { at risk }\end{array}$ & $\begin{array}{l}\text { Year TDI } \\
\text { introduced }\end{array}$ & $\begin{array}{l}\text { Last possible } \\
\text { year of employment }\end{array}$ \\
\hline A & 212 & 4198 & 1965 & 1984 \\
B & 722 & 12159 & 1958 & 1984 \\
C & 2940 & 59270 & 1962 & 1984 \\
D & 737 & 14766 & 1964 & 1982 \\
Total & 4611 & 90393 & & \\
\hline
\end{tabular}

and time since first exposure. Expected number of deaths during the follow up period was calculated by multiplying the United States sex, race, and cause specific death rates within each age, calendar periods, duration and time since first exposure (person years at risk) category. The resulting expected numbers were summed over strata to obtain cause specific and total expected numbers of deaths. The ratio of observed to expected deaths was expressed as the SMR. Ninety five per cent confidence intervals were computed for the
SMRs assuming a Poisson distribution for observed deaths.

\section{Results}

The figure shows the results of our assessments for TDI exposure (both isomers) and historical exposure data. Some data are missing in the early years, particularly for plant C. However, they indicate appreciably higher exposures in the past, especially before 1975 . Our measurement data also indicated that the 2,6-isomer was more prevalent in the air than the 2,4-isomer. ${ }^{12}$ Because historical measurements included only 2,4-TDI concentrations, combined 2,4 and 2,6 isomer exposures before 1980-6 may have been as high as twofold ${ }^{12}$ to 10-fold ${ }^{15}$ higher.

Additional exposures in the four study plants included intermittent methylene chloride exposure to some pouring line operators at plant $\mathrm{C}$ where concentrations ranged between 120 and $260 \mathrm{mg} / \mathrm{m}^{3}$. Methylene chloride exposures at the other plants were generally lower and more isolated. Aliphatic amines were detected at an air concentration of up to $1.4 \mathrm{mg} / \mathrm{m}^{3}$ at plant A. Nitrogen dioxide was found in very low quantities in plants $A$ and $C$. Acrolein and acrylonitrile were evident in the exhaust air in some locally ventilated operations at plant $\mathrm{C}$. All other chemical contaminants sampled were not detectable. However, mutagenic activity was increased in filter sample extracts collected inside the plants compared with samples collected outside the plants. The identity of the chemicals related to the mutagenic activity and the relevance to human health are not known. ${ }^{16}$

Tables 1 and 2 provide the characteristics of this young cohort. Only $6.9 \%(n=316)$ of the cohort had died at the end of the study. Of

Table 3 Mortality according to cause of death for all plants combined

\begin{tabular}{|c|c|c|c|c|}
\hline Cause of death (ICD-9 code) & Obs & $\operatorname{Exp}$ & $S M R$ & $95 \% C I$ \\
\hline 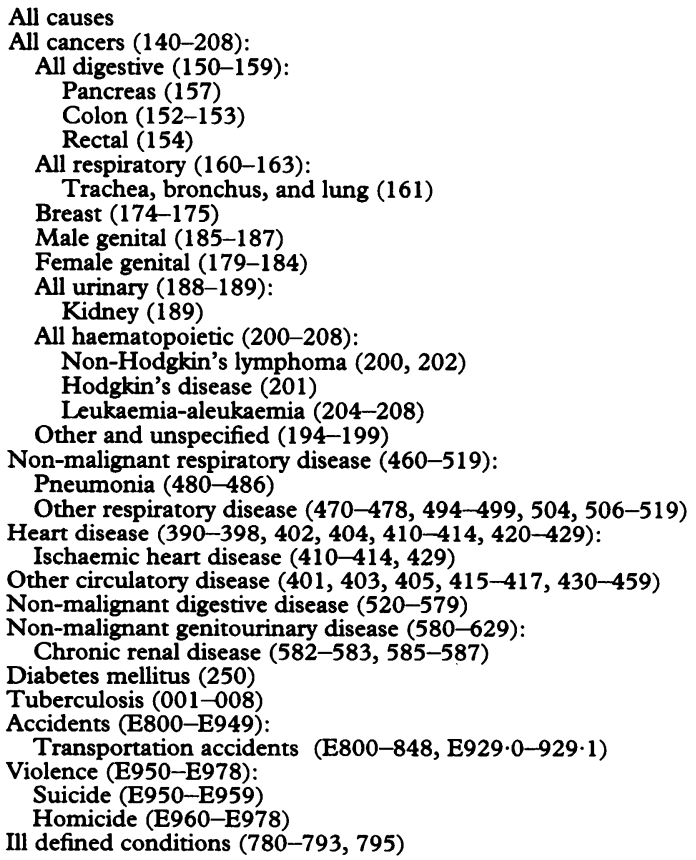 & $\begin{array}{r}316 \\
71 \\
11 \\
1 \\
2 \\
3 \\
21 \\
20 \\
6 \\
3 \\
3 \\
3 \\
2 \\
9 \\
4 \\
2 \\
3 \\
15 \\
13 \\
4 \\
9 \\
67 \\
54 \\
16 \\
15 \\
6 \\
4 \\
4 \\
1 \\
43 \\
29 \\
46 \\
25 \\
21 \\
6\end{array}$ & $\begin{array}{r}332 \cdot 75 \\
70.92 \\
15.46 \\
2.89 \\
5 \cdot 20 \\
1.08 \\
20.92 \\
19.85 \\
6.80 \\
2.34 \\
3.47 \\
2.24 \\
1.45 \\
7.37 \\
2.59 \\
0.86 \\
2.93 \\
10.31 \\
15.12 \\
6.09 \\
5.93 \\
73.22 \\
54.38 \\
20.69 \\
18.69 \\
4.08 \\
2.14 \\
5.92 \\
0.99 \\
4.43 \\
26.81 \\
36.73 \\
14.00 \\
22.73 \\
6.74\end{array}$ & $\begin{array}{l}0.95 \\
1.00 \\
0.71 \\
0.35 \\
0.38 \\
2.78 \\
1.00 \\
1.01 \\
0.88 \\
1.28 \\
0.86 \\
1.34 \\
1.38 \\
1.22 \\
1.54 \\
2.32 \\
1.02 \\
1.46 \\
0.86 \\
0.66 \\
1.52 \\
0.92 \\
0.99 \\
0.77 \\
0.80 \\
1.47 \\
1.87 \\
0.68 \\
1.01 \\
0.97 \\
1.08 \\
1.25 \\
1.79 \\
0.92 \\
0.89\end{array}$ & $\begin{array}{l}0 \cdot 85-1 \cdot 06 \\
0 \cdot 78-1 \cdot 26 \\
0 \cdot 35-1 \cdot 27 \\
0 \cdot 01-1.92 \\
0 \cdot 05-1 \cdot 39 \\
0 \cdot 57-8 \cdot 13 \\
0 \cdot 62-1 \cdot 53 \\
0 \cdot 62-1 \cdot 56 \\
0 \cdot 32-1 \cdot 92 \\
0 \cdot 26-3 \cdot 76 \\
0 \cdot 18-2 \cdot 53 \\
0 \cdot 28-3 \cdot 92 \\
0 \cdot 17-5 \cdot 00 \\
0 \cdot 56-2 \cdot 32 \\
0 \cdot 42-3 \cdot 95 \\
0 \cdot 28-8 \cdot 38 \\
0 \cdot 21-2 \cdot 99 \\
0 \cdot 81-2 \cdot 40 \\
0 \cdot 40-1 \cdot 47 \\
0 \cdot 18-1 \cdot 68 \\
0 \cdot 69-2 \cdot 88 \\
0 \cdot 71-1 \cdot 16 \\
0 \cdot 75-1.30 \\
0 \cdot 44-1.26 \\
0 \cdot 45-1 \cdot 32 \\
0 \cdot 54-3 \cdot 20 \\
0 \cdot 51-4 \cdot 78 \\
0 \cdot 18-1 \cdot 73 \\
0 \cdot 03-5 \cdot 63 \\
0 \cdot 70-1 \cdot 30 \\
0 \cdot 72-1 \cdot 55 \\
0 \cdot 92-1 \cdot 67 \\
1 \cdot 15-2 \cdot 63 \\
0 \cdot 57-1 \cdot 41 \\
0 \cdot 33-1 \cdot 94\end{array}$ \\
\hline
\end{tabular}


Table 4 Mortality (SMR (number of deaths)) for selected causes, according to duration of exposure to TDI

\begin{tabular}{|c|c|c|c|}
\hline \multirow[b]{2}{*}{ Cause of death } & \multicolumn{3}{|c|}{ Duration of exposure } \\
\hline & $<2 y$ & $2-10 y$ & $>10 y$ \\
\hline All cancers: & $1 \cdot 16(46)$ & $0.73(16)$ & $0.95(9)$ \\
\hline Lung & $1.33(14)$ & $0.48(3)$ & $0.96(3)$ \\
\hline Breast & $0.99(4)$ & $0.46(1)$ & $1.76(1)$ \\
\hline Rectal & $5 \cdot 15(3)^{\star}$ & $-\quad(0)$ & $-(0)$ \\
\hline All haematopoietic: & $1.54(7)$ & - (0) & $2 \cdot 65(2)$ \\
\hline Non-Hodgkin's lymphoma & $1.90(3)$ & $-\quad(0)$ & $4.02(1)$ \\
\hline Hodgkin's disease & $1.63(1)$ & $-(0)$ & $23.58(1)$ \\
\hline Leukaemia-aleukaemia & $1.63(3)$ & - (0) & $-\quad(0)$ \\
\hline Chronic renal disease & $0.80(1)$ & $4 \cdot 76(3)$ & (0) \\
\hline
\end{tabular}

$\star \mathrm{P}<0.05$.

Table 5 Mortality (SMR (number of deaths)) for selected cancers, according to duration of time since first exposure to TDI

\begin{tabular}{llll}
\hline & \multicolumn{4}{l}{ Time since first exposure } \\
\cline { 2 - 4 } Cause of death & $<10 y$ & $10-15 y$ & $>15 y$ \\
\hline All cancers: & $0.68(10)$ & $1.19(16)$ & $1.05(45)$ \\
Lung & $0.64(2)$ & $0.58(2)$ & $1.21(16)$ \\
Breast & $-\quad(0)$ & $1.24(2)$ & $1.12(4)$ \\
Rectal & $4 \cdot 21(1)$ & $4.93(1)$ & $1.57(1)$ \\
All haematopoietic: & $0.92(2)$ & $0.69(1)$ & $1.59(6)$ \\
$\quad$ Non-Hodgkin's lymphoma & $-\quad(0)$ & $-\quad(0)$ & $2.70(4)$ \\
$\quad$ Hodgkin's disease & $-\quad(0)$ & $-1.71(1)$ & $8.63(2)^{\star}$ \\
$\quad$ Leukaemia-aleukaemia & $2.09(2)$ & & $-(0)$ \\
\hline
\end{tabular}

$\star \mathrm{P}<0.05$.

Table 6 Mortality (SMR (number of observed deaths)) for selected causes, by sex

\begin{tabular}{lcl}
\hline Cause of death & Men & Women \\
\hline Cancers: & $0.79(12)$ & $1.73(8)$ \\
Lung & $18.52(1)$ & $0.74(5)$ \\
Breast & $3.90(0)$ & $1.11(2)$ \\
Colon & $1.16(6)$ & $1.36(0)$ \\
Rectal & $0.81(9)$ & $1.00(4)$ \\
All haematopoietic & $2.55(4)$ & $0.73(7)$ \\
Non-malignant respiratory disease & $1.05(47)$ & $0.74(7)$ \\
Chronic renal disease & $0.84(19)$ & $2.44(10)^{\star}$ \\
Ischaemic heart disease & $1.99(23)^{\star \star}$ & $0.81(2)$ \\
Transportation accidents & $0.68(13)$ & $2.80(7)^{\star}$ \\
Suicide & &
\end{tabular}

$\star \mathrm{P}<0.05 ;{ }^{\star \star} \mathrm{P}<0.01$. analyses in which exposure was lagged by five years, this pattern did not change, nor did the pattern change when analysis was limited to person-time after employment at the study plants or when analysis included multiple causes of death. ${ }^{17}$

As table 5 shows, all four cases of nonHodgkin's lymphoma (SMR $2 \cdot 70,95 \%$ CI 0.74-6.92) and both cases of Hodgkin's disease (SMR 8.63, 95\% CI 1.05-31.18) occurred in people with more than 15 years since first exposure to TDI. No other cancer showed an apparent trend with increased time since first exposure.

Table 6 shows mortality by sex. No single cause of death was consistently increased for both sex groups. Women had slightly higher mortality from lung cancer and all haematopoietic cancers than men. Men had slightly higher mortality from rectal cancer and chronic renal disease. Women had no increase in mortality from breast cancer (SMR 0.74, $\mathrm{n}=5$ ) and one male death from breast cancer resulted in an increased SMR for men. Mortality from suicide was significantly increased only among men (SMR 1.99, 95\% CI 1.26-2.99) and women had significantly increased mortality from homicide (SMR 2.80, 95\% CI $1 \cdot 12-5 \cdot 78)$ and transportation accidents (SMR 2.44 95\% CI 1·17-4.48).

\section{Discussion}

Although one previous publication presented increased lung and pancreatic cancer," we found no excess mortality from either cause. Another previous study of workers exposed to TDI found excess non-Hodgkin's lymphomas and rectal cancer. ${ }^{10} \mathrm{We}$ found non-significantly increased SMRs for both causes of death. Non-Hodgkin's lymphoma and Hodgkin's disease were the only cancers to show some increased mortality among workers with more than 15 years since first exposure, but there were few deaths in either category.

We did find some differences in cancer mortality by sex. The single case of male breast cancer is of interest because exposed female rats had an increased incidence of mammary gland fibroadenomas. ${ }^{7}$ However, women in the cohort did not have excess mortality from breast cancer and breast cancer incidence and mortality were not increased in the other two cohort studies. ${ }^{1011}$ Women seemed to have an increased SMR for lung cancer (SMR 1.73, 95\% CI 0.75-3.41), although men did not (SMR 0.79, 95\% CI $0 \cdot 41-1 \cdot 38$ ). Sorahan and Pope ${ }^{11}$ also found an increase in incidence and mortality of lung cancer among women and attributed it to cigarette smoking. It is possible that smoking might explain the lung cancer deaths in our study. However, mortality from ischaemic heart disease, also related to smoking, was not increased among women (SMR 0.73). Men showed a non-significant increase in mortality from renal disease. However, mortality from renal disease was not increased in the other cohort studies.
Table 4 shows mortality according to tion of exposure for selected causes of death. There were no apparent trends in cancer mortality with increased duration of exposure. In 
Although violent deaths were increased in this cohort, we did not find a direct relation with occupation. Homicide deaths did not occur at work and only one of the 21 deaths occurred while the worker was currently employed at the study plant. Two of the 25 suicides occurred while the workers were currently employed at the plant.

Air concentrations at all four plants declined appreciably over time. However, because air concentrations at the four plants were fairly similar within the periods studied and because there were so few deaths in this young cohort, we did not conduct an analysis of mortality by plant.

As few, if any, of the workers at the facilities wore gloves, skin contact with TDI could have occurred. Dermal absorption of TDI in rats topically dosed with TDI has been shown by the presence of toluenediamine in chemically hydrolysed urine. ${ }^{18}$ At the time that the exposure surveys were performed for this study, there were no methods available for assessing skin exposure or performing biological monitoring. The extent of absorption of TDI through the dermal route in the flexible foam manufacturing industry is as yet unknown.

This industry has many short term workers and our study excluded those workers employed for less than three months (over $50 \%$ of the population). The mortality experience of very short term workers might differ from that of those workers studied here.

We did not find increased mortality from cancer in this cohort with relatively short duration of exposure. However, the cohort is young, has small numbers of deaths, and short follow up. Our findings are therefore not conclusive.

We are indebted to Susan Palu, Kathy Masterson, and NIOSH clerical staff for their expertise and support. This research was funded in part by the National Cancer Institute.
1 Buist JM. Isocyanates in industry. Proceedings of the Royal Society of Medicine 1970;63:365-7.

2 National Institute for Occupational Safety and Health. Criteria for a recommended standard of occupational exposure to diisocyanate. Cincinnati, OH: US Department of Health Education and Welfare, 1978. (Publication No 78-215.)

3 Banks DE, Balaan MR. The respiratory effects of isocyanates. In: WN Rom, ed. Environmental and occupational medicine. Boston: Little, Brown, 1992.

4 Anderson M, Binderup M-L, Kiel P, Larsen H, Maxild J. Mutagenic action of isocyanates used in the production of polyurethanes. Scand 7 Work Environ Health 1980;6: $221-6$.

5 Persson P, Dalene M, Skarping G, Adamsson M, Hagmar L. Biological monitoring of occupational exposure to
toluene diisocyanate: measurement of toluenediamine in toluene diisocyanate: measurement of toluenediamine in
hydrolysed urine and plasma by gas chromatographymass spectrometry. Br f Ind Med 1993;50:1111-8.

6 Haseman JK, Crawford DD, Huff JE, Boorman GA McConnell EE. Results from 86 two-year carcinogenicity studies conducted by the National Toxicology Program. f Toxicol Environ Health 1984;14:621-39.

7 National Toxicology Program. Toxicology and carcinogenesis studies of commercial grade 2,4 (80\%)- and 2,6 (20\%)toluene diisocyanate (CAS No 2671-62-5) in F344/N rats and B6C3F1 mice (gavage studies). Research Triangle Park, North Carolina: US National Toxicology Program 86-2507).

8 Loeser E. Long-term toxicity and carcinogenicity studies with $2,4 / 2,6$ toluene-diisocyanate $(80 / 20)$ in rats and mice. Toxicol Lett 1983;15:71-81.

9 International Agency for Research on Cancer. Some chemicals used in plastics and elastomers. LARC Monogr Eval Carcinog Risks Hum 1986;39:287-323.

10 Hagmar L, Welinder H, Mikoczy Z. Cancer incidence and mortality in the Swedish polyurethane foam manufacturing industry. Br f Ind Med 1993;50:537-43.

11 Sorahan T, Pope D. Mortality and cancer morbidity of production workers in the United Kingdom flexible polyurethane foam industry. Br f Ind Med 1993;50: polyurethat

12 Boeniger $M$. Air concentrations of TDI and total reactive isocyanate group in three flexible polyurethane manufacturing facilities. Appl Occup Environ Hyg 1991;6:853-8.

13 Boeniger $M$. Non-isocyanate exposures in three flexible polyurethane manufacturing facilities. Appl Occup Environ Hyg 1991;6:945-52.

14 Steenland K, Beaumont J, Spaeth S, Brown D, Okun A Jurcenko $\mathbf{L}$, et al. New developments in the life table analysis system of the National Institute for Occupational analysis system of the National Institute for Occupat

15 Rando RJ, Abdel-Kader HA, Hammad YY. Isomeric composition of airborne TDI in the polyurethane foam indusposition of airborne TDI in the polyurethane
try. Am Ind Hyg Assoc $\mathcal{F} 1984 ; 45: 199-203$.

16 Ong T, Stewart J, Whong W, Boeniger M. Mutagenicity assessment of airborne particles from three polyurethan foam manufacturing facilities. Mut Res 1987;11:475-83.

17 Steenland K, Nowlin S, Ryan B, Adams S. Use of multiplecause mortality data in epidemiologic analyses: US rate and proportion files developed by the National Institute for Occupational Safety and Health and the National Cancer Institute. Am ₹ Epidemiol 1992;136:855-62.

18 Rosenberg C, Savolainen $\mathrm{H}$. Detection of urinary amine metabolites in toluene diisocyanate exposed rats. $\mathcal{F}$ Chromatography 1985;323:429-33. 